\title{
Separation and purification of cardol, cardanol and anacardic acid from cashew (Anacardium occidentale L.) nut-shell liquid using a simple two-step column chromatography
}

\author{
Maria Yuliana ${ }^{a}$, Bich Thuyen Nguyen-Thi ${ }^{a}$, Sitti Faika ${ }^{a}$, Lien Huong Huynh ${ }^{b}$, \\ Felycia Edi Soetaredjo ${ }^{\mathrm{c}}$, Yi-Hsu Ju ${ }^{\mathrm{a}, *}$ \\ a Department of Chemical Engineering, National Taiwan University of Science and Technology, 43, Keelung Road, Section 4, Taipei 10607, Taiwan \\ ${ }^{\mathrm{b}}$ Department of Chemical Engineering, Can Tho University, 3-2 Street, Can Tho City, Viet Nam \\ ${ }^{\mathrm{c}}$ Department of Chemical Engineering, Widya Mandala Surabaya Catholic University, Kalijudan 37, Surabaya 60114, Indonesia
}

\section{A R T I C L E IN F O}

\section{Article history:}

Received 23 March 2014

Received in revised form 30 June 2014

Accepted 15 July 2014

Available online 4 August 2014

\section{Keywords:}

Anacardium occidentale $\mathrm{L}$.

Cashew nut shell

Two-step column chromatography

Anacardic acid

Cardanol

Cardol

\begin{abstract}
A B S T R A C T
Long chain phenols contained in cashew nut shell liquid have important applications. Anacardic acids and cardols are extensively used in the pharmaceutical industry, while cardanols find use in resins, coating and polymer industries. In this work, a two-step reversed-phase silica gel column chromatography was employed to purify these major phenols in cashew nut shell liquid (CNSL). 6Pentadecyl salicylic acid $\left(\mathrm{C}_{22} \mathrm{H}_{36} \mathrm{O}_{3}, 98.8 \%\right.$ purity and $82.4 \%$ recovery), 5-pentadecyl resorcinol $\left(\mathrm{C}_{21} \mathrm{H}_{36} \mathrm{O}_{2}, 99.3 \%\right.$ purity and $80.7 \%$ recovery $)$ and 3-pentadecyl phenol $\left(\mathrm{C}_{21} \mathrm{H}_{36} \mathrm{O}, 99.2 \%\right.$ purity and $81.8 \%$ recovery) were successfully obtained and identified by ${ }^{1} \mathrm{H}$ and ${ }^{13} \mathrm{C}$ NMR, FTIR, mass spectrometry and elemental analysis.
\end{abstract}

(c) 2014 Taiwan Institute of Chemical Engineers. Published by Elsevier B.V. All rights reserved.

\section{Introduction}

Cashew (Anacardium occidentale L.) nut shell (CNS) is a byproduct of cashew production. It is a source of unsaturated longchain phenols, such as anacardic acids, anacardols, cardols and their isomers. Both anacardic acids and cardols were reported to have antitumor [1-3], antimicrobial [2], urease inhibitory [4], lipoxygenase activities [5] as well as uncoupling ability [6]. On the other hand, cardanols are widely used in coating and resin industry due to their outstanding resistance to softening action of mineral oil and high resistance to acids, alkalis, microbe, termite and insect. Anacardic acids are thermally labile and easily degraded to their corresponding cardanol by decarboxylation at high temperature [7].

Several studies have been done on the extraction of phenols from CNS. According to Tyman et al. [8], around $6.1 \mathrm{wt}$.\% (based on dry weight of CNS) of cashew nut shell liquid (CNSL) was extracted

\footnotetext{
Abbreviations: CNS, cashew nut shell; CNSL, cashew nut shell liquid; TLC, thin layer chromatography; HPLC, high performance liquid chromatography; RP, reversedphase.

* Corresponding author. Tel.: +886 27376612; fax: +88622737 6644 .

E-mail address: yhju@mail.ntust.edu.tw (Y.-H. Ju).
}

by soaking CNS in light petroleum for a week and then subjecting the half-processed shell to soxhlet extraction at $40-60{ }^{\circ} \mathrm{C}$ for $12 \mathrm{~h}$ with light petroleum as the solvent. They also reported that the yield increased to $25.7 \%$ (based on the total weight of cashew nut with shell) when shells were macerated and re-extracted again for another $10 \mathrm{~h}$. CNSL obtained consists of $19.72 \%$ cardols, $58.14 \%$ anacardic acids, $1.92 \%$ cardanols and $20.22 \%$ polymeric materials. Yuliana et al. [9] reported that CNSL extracted for $30 \mathrm{~h}$ by using methanol contains $28.64 \%$ cardanols, $19.06 \%$ anacardic acids, $45.27 \%$ cardols, $1.86 \% \beta$-sitosterol, $3.41 \%$ triacontene and a trace amount of polymeric materials.

Due to the different uses of anacardic acids, anacardols and cardols, it is important to separate and purify these compounds in order to identify their properties for specific applications. Microanalysis of phenolic acids is an important aspect in the biochemistry of many natural products [10]. Tyman et al. [8] showed that the polarities of compounds detected in CNSL were similar. Therefore, purification of individual compound is difficult to achieve. To date, only anacardic acid isomer (15:0) and (15:3) are available in the purified form.

This study proposed a facile method to separate these 3 major phenolic compounds from CNSL using column chromatography. 
This method has been known as the mainstay of modern chromatography for both analytical and preparative separations for the last four decades. Compared to high performance liquid chromatography (HPLC), column chromatography has several advantages such as low cost, simple, more flexible in application, has higher sensitivity and ability to detect the co-elution, a phenomenon in which two compounds with similar structures and polarities can exit the column at the same time. Column chromatography offers flexibility in adjusting column length, particle size of beads, column dimension (packing height to packing diameter ratio) and capping chemistry used without purchasing different columns.

Reversed-phase (RP) column chromatography is by far the most widely used technique because it is applicable to most compounds with low and moderate polarities. Majors [11] stated that octadecylsilane (C18) silica gel is the most commonly used phase in this method due to its stability over ionization that might occur in separation process. Due to the nature of target compounds (long chain phenols), separation using RP octadecylsilane silica gel column chromatography was employed in this work. Conditions such as column dimension, silica gel to sample ratio and mobile phase composition were investigated to obtain optimal separation of the three phenols.

\section{Materials and methods}

\subsection{Materials and chemicals}

CNSs were obtained from the waste of cashew (variety Venguria-4) nut production in a factory in Solo, Indonesia. They were grounded, sieved, and stored at $-4{ }^{\circ} \mathrm{C}$. CNSL was obtained by subjecting CNS to soxhlet extraction for $10 \mathrm{~h}$. The extraction solvent was methanol, petroleum ether or diethyl ether.

All solvents used in this study were of HPLC grade. Petroleum ether was purchased from Acros Organics (New Jersey, USA) while methanol (99.5\% purity), diethyl ether (99.0\% purity) and acetone (99.9\% purity) were obtained from Echo Chemical (Miao Li, Taiwan). Deionized water was provided from a Mixed Bed Deionizers model MB18-PVN/m9060 (Pure Aqua Inc., Santa Ana, CA). Chloroform (99.9\% purity) was supplied by Sigma Aldrich (St. Louis, MO).

RP silica gel, Siliabond C18, was provided by Silicycle (Quebec, Canada), while pre-coated thin layer chromatography (TLC) sheets ALUGRAM RP-18 W/UV 254 were obtained from Macherey-Nagel (Düren, Germany). Fast Blue B salt as reagent for TLC analysis was purchased from Sigma Aldrich (St. Louis, MO).

Both NMR sample tubes (model $10005 \mathrm{~mm} 400-500 \mathrm{MHz}$ L7in) and the dissolving solvent, deuterated chloroform $\left(\mathrm{CDCl}_{3}\right)$, as well as potassium bromide used to prepare the blank pellet in the FTIR analysis were purchased from Sigma Aldrich (St. Louis, MO).

\subsection{Dewaxing and degumming of CNSL}

Degumming was performed by mixing hot distilled water with crude CNSL $(1: 1, \mathrm{v} / \mathrm{v})$ in a $50 \mathrm{~cm}^{3}$ beaker. The beaker was then placed in a water bath $\left(60^{\circ} \mathrm{C}\right)$ equipped with a magnetic stirrer $(750 \mathrm{rpm})$ for $1 \mathrm{~h}$. After degumming, the mixture was cooled to room temperature and centrifuged $(2000 \times \mathrm{g}, 30 \mathrm{~min})$. The degummed CNSL was decanted, dried and weighed.

Wax was separated by adding acetone $\left(-5^{\circ} \mathrm{C}\right)$ to the degummed CNSL $(1: 1, \mathrm{v} / \mathrm{v})$. The mixture was stored at $-5{ }^{\circ} \mathrm{C}$ for $24 \mathrm{~h}$ before subjected to centrifugation $(4000 \times \mathrm{g}, 30 \mathrm{~min})$. The wax formed was separated by decantation, dried in an oven and weighed. The dewaxed and degummed CNSL will be referred to as CNSL hereafter.

\subsection{Purification of phenols by RP silica gel column chromatography}

RP silica gel Siliabond C18 was activated overnight at $100{ }^{\circ} \mathrm{C}$ under vacuum. Three columns with different column height to column diameter ratio $(4: 1,6: 1$ and $8: 1)$ were prepared. The activated silica gel was placed in a column with two cylindrical polyethylene frits placed at both ends. The top of the column was then gently filled with methanol. Around $30 \mathrm{~cm}^{3}$ methanol was passed through the column bed in order to clean the column before use.

Fig. 1 shows the general procedure of column chromatography of phenols. Three columns with sample to silica gel ratio of $1: 20$, 1:50 and 1:100 (w/w) were prepared. After placing sample at the top of the column, the column bed was filled with methanol and it was let to pass through the column by gravity. Ten fractions $\left(0.5 \mathrm{~cm}^{3}\right.$ each) were collected. After completing the elution, the column was washed by chloroform. All fractions collected were then subjected to TLC analysis (Section 2.4). Fractions that contained more than one phenol were subjected to another column chromatography. This process was repeated until pure compounds were obtained. The isolated compounds were then carefully kept in a tight vial at $-20^{\circ} \mathrm{C}$ before further analyses.

\subsection{TLC analysis}

A specific reagent was used for detecting phenols in TLC analysis. This reagent was prepared by dissolving $300 \mathrm{mg}$ Fast Blue $B$ in $25 \mathrm{~cm}^{3}$ acetone-water mixture $(9: 1, \mathrm{v} / \mathrm{v})$. The desired spot will show red-violet color. Methanol was used as the mobile phase. The reagent was sprayed uniformly until the desired spot appeared.

\subsection{HPLC analysis}

Purity and recovery of phenols obtained from column chromatography were determined using a $5 \mu \mathrm{m}$ Phenomenex Luna C18 column $(240 \mathrm{~mm} \times 4.6 \mathrm{~mm}$; Phenomenex, Torrance, CA), with a flow rate of $1 \mathrm{~cm}^{3} / \mathrm{min}$ and an injection volume of $2 \times 10^{-2} \mathrm{~cm}^{3}$. Peaks were detected with a Jasco UV-2077 multiwavelength detector at 254, 278 and $300 \mathrm{~nm}$. The eluting solvent (methanol) was delivered using a Jasco PU-2089 pump for $20 \mathrm{~min}$. Peaks were identified by using elemental analysis, nuclear magnetic resonance (NMR) spectroscopy, FTIR and mass spectrometry.

\subsection{Compound identification analyses}

${ }^{1} \mathrm{H}-\mathrm{NMR}$ and ${ }^{13} \mathrm{C}$-NMR spectra were recorded on a Bruker AVANCE III $500 \mathrm{MHz}$ Fourier-transform NMR spectrometer using tetramethylsilane (TMS) as the reference substance and deuterated chloroform as the solvent. Distortionless enhancement by polarization transfer (DEPT) spectra was also measured to identify the structure of phenols. The IR spectra were recorded on a Bio-Rad FTS-40 FTIR Spectrophotometer with $\mathrm{KBr}$ pellets as the blank. An average of 32 scans per sample was made. Mass spectra were obtained by using a Finnigan LCQ Mass Spectrometer. A Perkin Elmer $240 \mathrm{C}$ elemental analyzer was used for elemental analysis.

\section{Results and discussion}

\subsection{Purification of three major phenolics}

Preliminary TLC analysis of CNSL (Fig. 2) showed that the polarities of the 3 major phenols in CNSL are close to each other. This indicates that it is difficult to separate these 3 major phenolics. According to their polarity, compounds A, B, and C are tentatively identified as cardanol, cardol and anacardic acid, respectively. 



1st step column chromatography

fraction 1



fraction 3
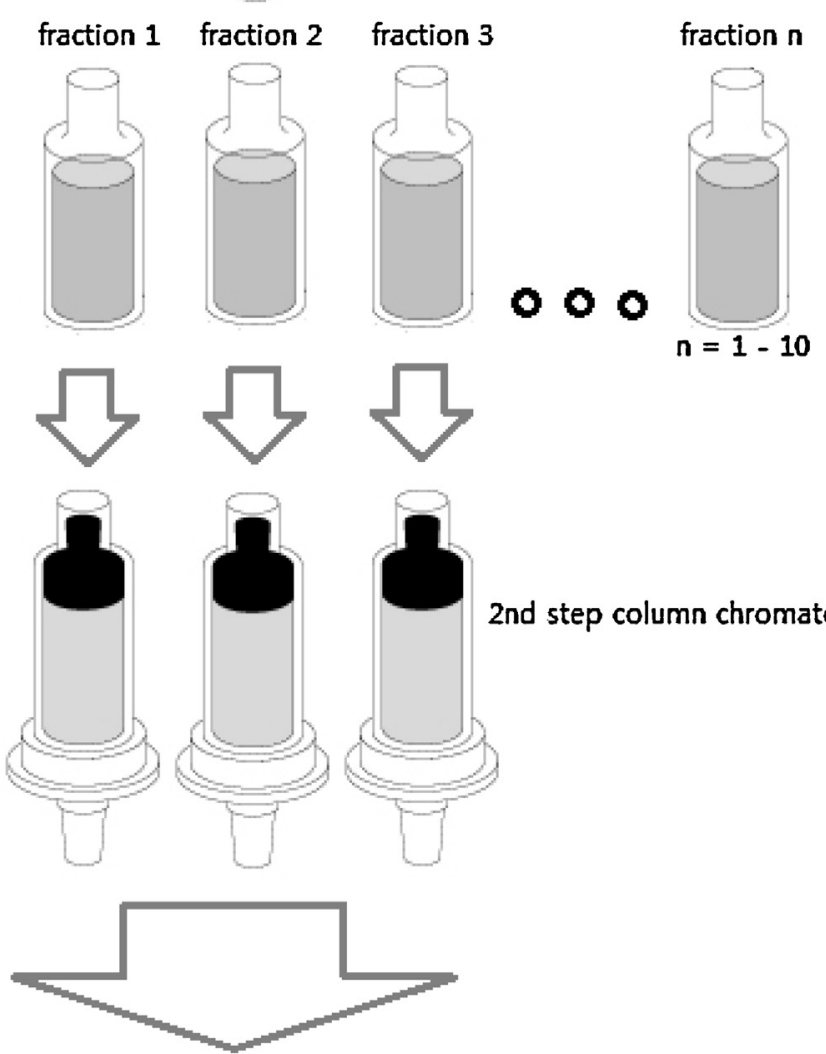

2nd step column chromatography
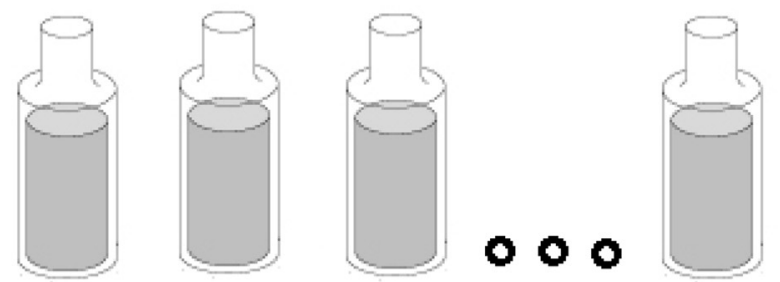

fraction $n .1$ fraction $n 2$ fraction $n .3$

fraction n.m

$m=1-10$

Fig. 1. Two-step RP silica gel column chromatography procedure.

In this work, three column height to diameter ratios $(4: 1,6: 1$, $8: 1)$, three CNSL to silica gel ratios $(1: 20,1: 50,1: 100, w / w)$ and three mobile phases (methanol, methanol/acetonitrile $(1: 1, \mathrm{v} / \mathrm{v})$, acetonitrile) were employed to study their effects on separation. Each fraction obtained from column chromatography was subjected to TLC and HPLC analyses.

\subsubsection{Effect of column height to diameter ratio on separation}

As column height to diameter ratio was increased from $4: 1$ to $8: 1$, significant increase in the purity of compound A, B and C was observed in the $3 \mathrm{rd}, 2$ nd and 1 st fraction, respectively (Table 1 ). On the other hand, the recoveries of those phenols were found to decrease slightly with increasing column height to diameter ratio. In RP column chromatography, longer column bed length results in retaining more non-polar compound longer in the RP-silica gel bed when column is eluted with mobile phase. This in turn lengthens both the retention time of each compound to be eluted and the retention time interval between two consecutive compounds eluted. Thus, in principle, only the most polar compound in the mixture will be collected in the first few fractions. Liu et al. [12] worked with peptide separation and reported that by using a longer column it was possible to lengthen the run-to-run time due to both the delayed peptide retention time and a longer column reequilibrium time. These factors affected the time required to 




Fig. 2. TLC chromatogram of methanolic extract of CNSL (mobile phase = methanol). complete a full chromatography run, even there was only a $7 \%$ increase in the net consuming time with a doubled column height to diameter ratio.

A column height to diameter ratio of 8:1 was chosen for further studies. This is because at this ratio, purities of phenols obtained are significantly higher than those obtained by using lower ratios. On the other hand, the effect of column height to diameter ratio on phenol recovery is insignificant.

\subsubsection{Effect of CNSL to silica gel ratio on separation}

Table 2 shows the effect of sample to silica gel ratio on purity and recovery of phenols. Compound $C$ was used as the indicator to observe the effect of CNSL to silica gel ratio. It can be seen that there is only slightly differences in the purities of anacardic acid among the three CNSL to silica gel ratios studied. However, the recovery of compound C decreases significantly from $88.3 \%$ to $63.4 \%$ as CNSL to silica gel ratio decreases from $1: 20$ to $1: 100$. Contents and recoveries of compound $\mathrm{B}$ in fraction 2 and compound $\mathrm{A}$ in fraction 3 follow similar trend as that of compound $C$ (data not shown). Purity changed only slightly as CNSL to silica gel ratio was decreased, but recovery decreased substantially with decreasing CNSL to silica gel ratio. A CNSL to silica gel ratio larger than 1:20 resulted in unsuccessful separation (data not shown) because it is larger than the linear capacity of the column [13]. This phenomenon is also likely due to the binding capacity of silica gel on CNSL. At a decreased CNSL to silica gel ratio, CNSL will have more access to the immobilized hydrophobic ligands and bound stronger to the available surface of RP-silica gel which will result in lower recovery when the same amounts of mobile phase and eluent are used. Gunawan et al. [14] also reported that more silica gel gave higher adsorption area available per unit non-polar lipid fraction, which resulted in longer elution time with comparable separation due to higher amount of mobile phase that was required to displace fatty acid steryl esters.

Besides resulting in higher recovery, a higher CNSL to silica gel ratio is desirable because less adsorbents and shorter elution time are required. Thus, a CNSL to silica gel ratios of 1:20 (w/w) was chosen in RP column chromatography.

\subsubsection{Effect of organic solvent composition on separation}

In general, RP column chromatography uses mixture of a buffer component, an organic solvent (modifier) and an ion pairing agent as mobile phase to affect selectivity. Buffer component and ion pairing agent are mostly used for peptide and protein separation. In phenol separation, a single organic solvent is usually used. Using single solvent as mobile phase is desirable because of easier

Table 1

Effect of column height to diameter ratio on purity and recovery of anacardic acid, cardol and cardanol in 1 st, 2nd and 3rd fractions ${ }^{\mathrm{a}}$.

\begin{tabular}{|c|c|c|c|c|c|c|}
\hline \multicolumn{7}{|l|}{ 1st Fraction } \\
\hline \multirow[t]{2}{*}{ Compound } & \multicolumn{2}{|c|}{ Column height/diameter $=4: 1$} & \multicolumn{2}{|c|}{ Column height/diameter $=6: 1$} & \multicolumn{2}{|c|}{ Column height $/$ diameter $=8: 1$} \\
\hline & Purity (wt.\%) & Recovery (wt.\%) & Purity (wt.\%) & Recovery (wt.\%) & Purity (wt.\%) & Recovery (wt.\%) \\
\hline $\mathrm{C}$ & $57.8 \pm 1.2$ & $90.5 \pm 1.6$ & $71.2 \pm 2.2$ & $88.4 \pm 1.4$ & $87.8 \pm 1.2$ & $86.6 \pm 3.4$ \\
\hline B & $31.0 \pm 1.1$ & $7.6 \pm 0.7$ & $21.1 \pm 0.9$ & $7.0 \pm 0.8$ & $8.7 \pm 0.5$ & $5.4 \pm 0.7$ \\
\hline A & $11.1 \pm 0.3$ & $3.5 \pm 0.2$ & $7.7 \pm 0.5$ & $3.3 \pm 0.6$ & $3.4 \pm 0.2$ & $2.2 \pm 0.8$ \\
\hline \multicolumn{7}{|l|}{ 2nd Fraction } \\
\hline \multirow[t]{2}{*}{ Compound } & \multicolumn{2}{|c|}{ Column height/diameter $=4: 1$} & \multicolumn{2}{|c|}{ Column height/diameter $=6: 1$} & \multicolumn{2}{|c|}{ Column height/diameter $=8: 1$} \\
\hline & Purity (wt.\%) & Recovery (wt.\%) & Purity (wt.\%) & Recovery (wt.\%) & Purity (wt.\%) & Recovery (wt.\%) \\
\hline $\mathrm{C}$ & $19.5 \pm 2.2$ & $10.1 \pm 2.8$ & $11.6 \pm 1.4$ & $9.0 \pm 2.9$ & $6.6 \pm 0.1$ & $8.7 \pm 1.3$ \\
\hline B & $61.6 \pm 1.3$ & $91.4 \pm 0.3$ & $77.8 \pm 0.7$ & $88.1 \pm 1.3$ & $89.0 \pm 2.3$ & $84.2 \pm 0.1$ \\
\hline A & $19.0 \pm 2.4$ & $8.2 \pm 0.2$ & $10.6 \pm 0.1$ & $7.9 \pm 0.1$ & $4.4 \pm 0.9$ & $6.2 \pm 0.1$ \\
\hline \multicolumn{7}{|l|}{ 3rd Fraction } \\
\hline \multirow[t]{2}{*}{ Compound } & \multicolumn{2}{|c|}{ Column height/diameter $=4: 1$} & \multicolumn{2}{|c|}{ Column height/diameter $=6: 1$} & \multicolumn{2}{|c|}{ Column height/diameter $=8: 1$} \\
\hline & Purity (wt.\%) & Recovery (wt.\%) & Purity (wt.\%) & Recovery (wt.\%) & Purity (wt.\%) & Recovery (wt.\%) \\
\hline $\mathrm{C}$ & $21.1 \pm 3.3$ & $10.9 \pm 3.5$ & $9.8 \pm 1.2$ & $10.0 \pm 1.3$ & $4.0 \pm 0.4$ & $5.9 \pm 0.0$ \\
\hline B & $20.2 \pm 0.1$ & $11.4 \pm 3.2$ & $13.5 \pm 0.7$ & $10.1 \pm 2.7$ & $7.2 \pm 1.7$ & $8.4 \pm 0.5$ \\
\hline A & $58.8 \pm 1.6$ & $88.7 \pm 1.1$ & $76.7 \pm 3.4$ & $87.2 \pm 1.2$ & $88.7 \pm 1.4$ & $85.4 \pm 1.0$ \\
\hline
\end{tabular}

\footnotetext{
a Average of three independent experiments.
} 
Table 2

Effect of CNSL to silica gel ratio on purity and recovery of compounds A, B and C in 1st fraction ${ }^{\mathrm{a}}$.

\begin{tabular}{|c|c|c|c|c|c|c|}
\hline \multirow[t]{2}{*}{ Compound } & \multicolumn{2}{|c|}{ CNSL/silica gel = 1:20 (w/w) } & \multicolumn{2}{|c|}{ CNSL/silica gel = 1:50 $(\mathrm{w} / \mathrm{w})$} & \multicolumn{2}{|c|}{ CNSL/silica gel = 1:100 $(\mathrm{w} / \mathrm{w})$} \\
\hline & Purity (wt.\%) & Recovery (wt.\%) & Purity (wt.\%) & Recovery (wt.\%) & Purity (wt.\%) & Recovery (wt.\%) \\
\hline A & $4.4 \pm 0.1$ & $2.5 \pm 0.1$ & $2.9 \pm 0.2$ & $1.3 \pm 0.3$ & $1.7 \pm 1.2$ & $0.7 \pm 0.0$ \\
\hline B & $8.8 \pm 0.0$ & $5.3 \pm 0.0$ & $5.9 \pm 1.2$ & $2.7 \pm 0.2$ & $4.8 \pm 0.2$ & $1.8 \pm 0.1$ \\
\hline $\mathrm{C}$ & $86.8 \pm 2.2$ & $88.3 \pm 3.5$ & $91.2 \pm 1.8$ & $79.1 \pm 3.3$ & $93.5 \pm 2.1$ & $63.4 \pm 2.2$ \\
\hline
\end{tabular}

a Average of three independent experiments.

Table 3

Effect of mobile phase composition on purity and recovery of compound A, B and C in 1st fraction ${ }^{\mathrm{a}}$.

\begin{tabular}{|c|c|c|c|c|c|c|}
\hline \multirow[t]{2}{*}{ Compound } & \multicolumn{2}{|l|}{ Pure methanol } & \multicolumn{2}{|c|}{ Methanol/acetonitrile $=1: 1(\mathrm{v} / \mathrm{v})$} & \multicolumn{2}{|c|}{ Pure acetonitrile } \\
\hline & Purity (wt.\%) & Recovery (wt.\%) & Purity (wt.\%) & Recovery (wt.\%) & Purity (wt.\%) & Recovery (wt.\%) \\
\hline A & $4.9 \pm 0.3$ & $0.2 \pm 0.0$ & $7.1 \pm 0.3$ & $0.2 \pm 0.1$ & $7.9 \pm 0.0$ & $0.1 \pm 0.1$ \\
\hline B & $7.8 \pm 1.0$ & $6.8 \pm 1.2$ & $10.7 \pm 0.4$ & $5.5 \pm 0.7$ & $12.4 \pm 0.2$ & $1.8 \pm 0.1$ \\
\hline $\mathrm{C}$ & $87.3 \pm 1.1$ & $87.2 \pm 1.4$ & $82.2 \pm 1.6$ & $84.6 \pm 1.5$ & $79.7 \pm 1.5$ & $79.9 \pm 3.5$ \\
\hline
\end{tabular}

a Average of three independent experiments.

recovery and reuse of solvent. The two most widely used organic solvents are acetonitrile and methanol because of their strong eluting abilities and UV transparent.

In this work, pure methanol, a mixture of methanol and acetonitrile $(1: 1, v / v)$ and pure acetonitrile were used to investigate the effect of mobile phase on purity and recovery of phenols. From Table 3, it can be seen that the purity of compound $C$ in the first fraction decreased from $87.3 \%$ to $79.7 \%$ when the mobile phase was changed from methanol to acetonitrile, with a corresponding decrease in the recovery of compound $\mathrm{C}$ from $87.2 \%$ to $79.9 \%$. This phenomenon is likely due to the effect of polarity of mobile phase. The lower the polarity of the solvent mixture, the higher its elution power is. Aside from polarity, Snyder and Kirkland [13] reported that mobile phase of low viscosity, such as methanol, is favored in order to maintain high column efficiency. Therefore, pure methanol was chosen as the mobile phase for further studies.

\subsection{Two-step RP silica gel column chromatography}

Table 4 shows the fractionation results of CNSL obtained by the first-step column chromatography (column height to diameter ratio $=8: 1$, CNSL to silica gel ratio $=1: 20$, mobile phase $=$ pure methanol). Compound $\mathrm{C}$ in the 1 st fraction has a purity of $87.0 \%$ and a recovery of $87.0 \%$, while compound B with a purity of $88.3 \%$ and a recovery of $85.7 \%$ was obtained in the 2 nd fraction. In the 3 rd fraction, compound A was collected with a purity of $87.9 \%$ and a recovery of $86.1 \%$. A 2nd step column chromatography was conducted for achieving higher purity of phenols. Operation conditions for the second-step column chromatography are the same as those of the first step.

As shown in Table 5, two-step column chromatography was successful in obtaining compound A, B and C with high purities and satisfactory recoveries. Compound C with $98.8 \%$ purity, compound B with $99.3 \%$ purity and compound A with $99.2 \%$ purity were obtained after the 2 nd column chromatography. The overall recoveries of compound $A, B$ and $C$ are all about $81 \%$ which is only slightly smaller than the recoveries achieved by single step column chromatography ( $85 \%$ to $87 \%$ ). This may be because when the eluted fractions were subjected to a second column chromatography, the retention time between two consecutive phenols were again lengthened, making it easier to purify a compound without sacrificing the recovery substantially.

Table 4

Fractionation of CNSL obtained by single step RP silica gel column chromatogaphy ${ }^{\mathrm{a}}$.

\begin{tabular}{|c|c|c|c|c|}
\hline \multirow[t]{2}{*}{ Compound } & CNSL & 1st Fraction ${ }^{\mathrm{b}}$ & 2nd Fraction ${ }^{\mathrm{b}}$ & 3rd Fraction $^{\mathrm{b}}$ \\
\hline & Content (wt.\%) & Content (wt.\%) and recovery (\%) & Content (wt.\%) and Recovery (\%) & Content (wt.\%) and recovery (\%) \\
\hline A & $28.6 \pm 1.8$ & $4.2 \pm 0.6(3.3 \pm 0.0)$ & $5.8 \pm 0.3(7.1 \pm 0.1)$ & $87.9 \pm 0.2(86.1 \pm 1.2)$ \\
\hline B & $45.3 \pm 0.2$ & $8.8 \pm 0.6(6.0 \pm 0.2)$ & $88.3 \pm 2.6(85.7 \pm 0.3)$ & $7.0 \pm 0.3(9.2 \pm 0.8)$ \\
\hline $\mathrm{C}$ & $19.1 \pm 1.2$ & $87.0 \pm 0.1(87.0 \pm 1.2)$ & $6.0 \pm 0.2(9.3 \pm 0.5)$ & $5.1 \pm 1.4(7.0 \pm 0.3)$ \\
\hline Others & $7.0 \pm 0.1$ & ND & ND & ND \\
\hline
\end{tabular}

a Average of three independent experiments.

b 1 st, 2nd, 3rd fraction: fractions which were obtained from the single step column chromatography of CNSL.

Table 5

Fractionation of CNSL obtained by two-step RP silica gel column chromatogaphy ${ }^{\mathrm{a}}$.

\begin{tabular}{|c|c|c|c|c|}
\hline \multirow[t]{2}{*}{ Compound } & CNSL & Fraction $1.1^{\mathrm{b}}$ & Fraction $2.2^{\mathrm{c}}$ & Fraction $3.3^{\mathrm{d}}$ \\
\hline & Content (wt.\%) & Content (wt.\%) and recovery (\%) & Content (wt.\%) and Recovery (\%) & Content (wt.\%) and recovery (\%) \\
\hline A & $28.6 \pm 1.8$ & ND & $0.5 \pm 0.1(0.7 \pm 0.1)$ & $99.2 \pm 1.1(81.8 \pm 2.3)$ \\
\hline B & $45.3 \pm 0.2$ & $1.2 \pm 0.0(0.7 \pm 0.1)$ & $99.3 \pm 1.3(80.7 \pm 1.2)$ & $0.8 \pm 0.1(1.1 \pm 0.2)$ \\
\hline $\mathrm{C}$ & $19.1 \pm 1.2$ & $98.8 \pm 1.1(82.4 \pm 0.3)$ & $0.2 \pm 0.0(0.3 \pm 0.0)$ & ND \\
\hline Others & $7.0 \pm 0.1$ & ND & ND & ND \\
\hline
\end{tabular}

${ }^{a}$ Average of three independent experiments.

b Fraction 1.1: the first fraction obtained from the fractionation of 1 st fraction of Table 4.

c Fraction 2.2: the second fraction obtained from the fractionation of 2nd fraction of Table 4.

d Fraction 3.3: the third fraction obtained from the fractionation of 3rd fraction of Table 4. 

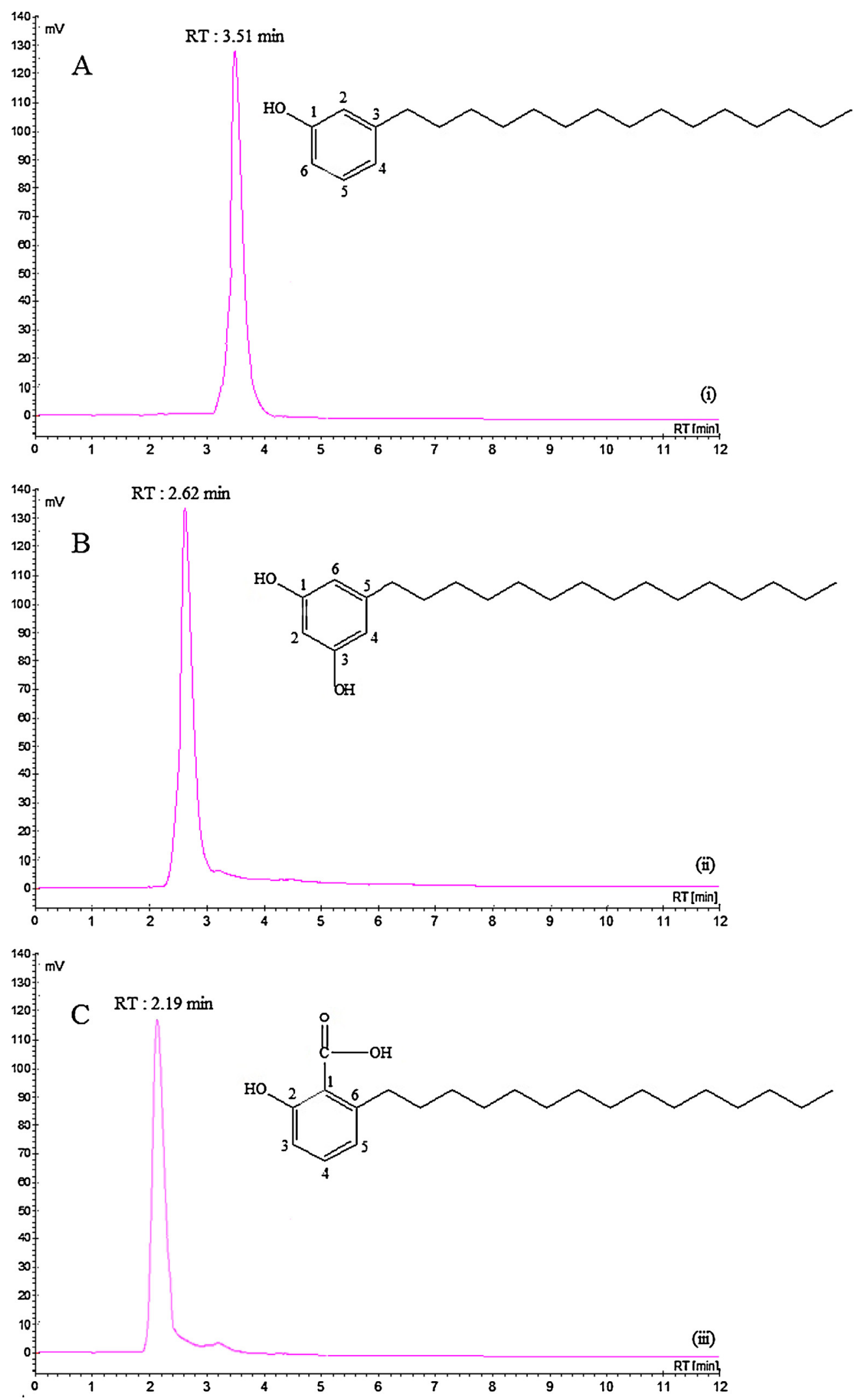

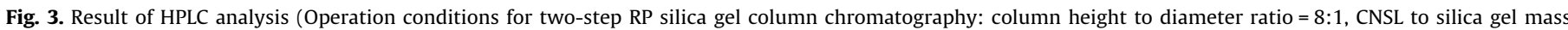
ratio $=1: 20$ and methanol as mobile phase) and the structure of (i) compound A (ii) compound B and (iii) compound C

Fig. 3 shows the HPLC chromatograms of the purified compound $\mathrm{A}, \mathrm{B}$ and $\mathrm{C}$ which has a retention time of $3.51 \mathrm{~min}, 2.81 \mathrm{~min}$ and $2.43 \mathrm{~min}$, respectively. Since standards of anacardic acid, cardol and cardanol were unavailable, the tentatively identified compounds of these three phenols have to be confirmed by analyses including ${ }^{1} \mathrm{H}$ and ${ }^{13} \mathrm{C}$ NMR, FTIR, mass spectrometry and elemental analysis.

The characterization of compound A, B and C are summarized below: 
Compound A ${ }^{13} \mathrm{C}$ NMR $\left(\mathrm{CDCl}_{3}, \delta\right): 13.779\left(-\mathrm{CH}_{3}\right), 22.643-$ $31.977\left(\left(-\mathrm{CH}_{2}-\right)_{14}\right), 128.149(\mathrm{C}-4), 129.914(\mathrm{C}-6), 130.384(\mathrm{C}-3)$, $135.423(\mathrm{C}-5), 136.816(\mathrm{C}-2), 147.768(\mathrm{C}-1) .{ }^{1} \mathrm{H}$ NMR $\left(\mathrm{CDCl}_{3}, \delta\right)$ : $0.846\left(3 \mathrm{H}, \mathrm{CH}_{3}\right), 1.243-1.619\left(28 \mathrm{H}, \mathrm{CH}_{2}\right), 6.675(1 \mathrm{H}, \mathrm{H}-5), 6.767$ $(1 \mathrm{H}, \mathrm{H}-4), 6.882(1 \mathrm{H}, \mathrm{H}-6), 7.240(1 \mathrm{H}, \mathrm{OH}), 7.343(2 \mathrm{H}, \mathrm{H}-2) . \mathrm{IR}(\mathrm{KBr})$ : 589, 712, 819, 904, 987, 1214, 1247, 1304, 1449, 1647, 2855, 2925, $3009 \mathrm{~cm}^{-1}$. Elemental analysis found: C, $82.67 \%, \mathrm{H}, 11.90 \%, \mathrm{~N}$ $0.22 \%, 0,5.21 \% . m / z: 304.2$.

Compound B ${ }^{13} \mathrm{C}$ NMR $\left(\mathrm{CDCl}_{3}, \delta\right): 14.076\left(-\mathrm{CH}_{3}\right), 27.197-$ $31.959\left(\left(-\mathrm{CH}_{2}-\right)_{14}\right), 126.802$ (C-4), 127.569 (C-6), 130.112 (C-5), 136.810 (C-2), 146.086 (C-3), 147.655 (C-1). ${ }^{1} \mathrm{H}$ NMR $\left(\mathrm{CDCl}_{3}, \delta\right)$ : $0.894\left(3 \mathrm{H}, \mathrm{CH}_{3}\right), 1.245-1.599\left(28 \mathrm{H}, \mathrm{CH}_{2}\right), 6.223(2 \mathrm{H}, \mathrm{OH}), 6.858(1 \mathrm{H}$, H-2), 7.331 (2H, H-4, H-6). IR (KBr): 584, 716, 827, 910, 994, 1162, $1213,1245,1303,1452,1645,2856,2927,3010 \mathrm{~cm}^{-1}$. Elemental analysis found: $\mathrm{C}, 78.68 \%, \mathrm{H}, 11.25 \%, \mathrm{~N}, 0.20 \%, \mathrm{O}, 9.87 \% . \mathrm{m} / \mathrm{z}: 320.1$.

Compound ${ }^{13} \mathrm{C}$ NMR $\left(\mathrm{CDCl}_{3}, \delta\right): 14.105\left(-\mathrm{CH}_{3}\right), 27.201-$ $32.754\left(\left(-\mathrm{CH}_{2}-\right)_{14}\right), 96.113$ (heteroaromatic substitution), 126.824 $\left(\mathrm{C}_{6} \mathrm{H}_{5}-\right), 127.590$ (C-5), 129.293 (C-3), 130.381 (C-4), 134.963 (C1), 136.837 (C-6), 156.710 (C-2), $163.567(-\mathrm{C}(=\mathrm{O}) \mathrm{OH}) .{ }^{1} \mathrm{H}$ NMR $\left(\mathrm{CDCl}_{3}, \delta\right): 0.873\left(3 \mathrm{H}, \mathrm{CH}_{3}\right), 1.263-1.781\left(28 \mathrm{H}, \mathrm{CH}_{2}\right), 6.601(1 \mathrm{H}$, $\mathrm{OH}), 7.240(1 \mathrm{H}, \mathrm{C}(=\mathrm{O}) \mathrm{OH}), 6.717(1 \mathrm{H}, \mathrm{H}-4), 6.838(1 \mathrm{H}, \mathrm{H}-3), 7.310$ (1H, H-5). IR (KBr): 763, 1038, 1210, 1351, 1449, 1614, 2928, $3368 \mathrm{~cm}^{-1}$. Elemental analysis found: $\mathrm{C}, 75.9 \%, \mathrm{H}, 10.33 \%, \mathrm{~N}, 0.76 \%$, O, $13.01 \% . m / z: 348.8$.

Elemental analysis, NMR spectra, IR spectra and MS analysis confirmed the structure of all compounds reported. The compound characterizations determined that compound $\mathrm{A}, \mathrm{B}$ and $\mathrm{C}$ have the structure as depicted in Fig. 3. A is 3-pentadecyl phenol $\left(\mathrm{C}_{21} \mathrm{H}_{36} \mathrm{O}\right)$, an isomer of cardanol, and $\mathrm{B}$ is 5-pentadecyl resorcinol $\left(\mathrm{C}_{21} \mathrm{H}_{36} \mathrm{O}_{2}\right)$, an isomer structure of cardol, while $\mathrm{C}$ is 6-pentadecyl salicylic acid $\left(\mathrm{C}_{22} \mathrm{H}_{36} \mathrm{O}_{3}\right)$, an isomer anacardic acid. The results are in agreement with those of Kim et al. [15] and Maia et al. [16].

\section{Conclusions}

A two-step RP silica gel column chromatography was successfully applied to purify isomers of anacardic acid, cardanol and cardol. The proper conditions needed to obtain these results are as follows: CNSL to silica gel mass ratio of $1: 20$, column height to diameter ratio of 8:1 and methanol as mobile phase. Under these conditions, 6-pentadecyl salicylic acid $\left(\mathrm{C}_{22} \mathrm{H}_{36} \mathrm{O}_{3}\right.$, a saturated isomer of anacardic acid) with $98.8 \%$ purity and $82.4 \%$ recovery, 5-pentadecyl resorcinol $\left(\mathrm{C}_{21} \mathrm{H}_{36} \mathrm{O}_{2}\right.$, a saturated isomer of cardol) with $99.3 \%$ purity and $80.7 \%$ recovery, and 3-pentadecyl phenol $\left(\mathrm{C}_{21} \mathrm{H}_{34} \mathrm{O}\right.$, a saturated isomer of cardanol) with $99.2 \%$ purity and $81.8 \%$ recovery were obtained.

\section{Acknowledgements}

This work was supported by Ministry of Science and Technology of Taiwan (NSC 98-2221-E-011-046-MY3) and National Taiwan University of Science and Technology (100H451403).

\section{References}

[1] Melo Cavalcante AA, Rübensam G, Erdtmann B, Brendel M, Henriques JAP. Cashew (Anacardium occidentale) apple juice lowers mutagenicity of aflatoxin B1 in S. typhimurium TA102. Genet Mol Biol 2005;28:328-33.

[2] Kubo I, Ochi M, Vieira PC, Komatsu S. Antitumor agents from the cashew (Anacardium occidentale) apple juice. J Agric Food Chem 1993;41:1012-5.

[3] Kozubek A, Zamowski R, Stasiuk M, Gubernator J. Natural amphiphilic phenols as bioactive compounds. Cell Mol Biol Lett 2001;6:351-5.

[4] Kubo J, Lee JR, Kubo I. Anti-Helicobacter pylori agents from the cashew apple. J Agric Food Chem 1999;47:533-7.

[5] Ha TJ, Kubo I. Lipoxygenase inhibitory activity of anacardic acids. J Agric Food Chem 2005;53:4350-4.

[6] Toyomizu M, Okamoto K, Ishibashi T, Chen ZQ, Nakatsu T. Uncoupling effect of anacardic acids from cashew nut shell oil on oxidative phosphorylation of rat liver mitochondria. Life Sci 2000;66:229-34.

[7] Philip JYN, Fransisco JDC, Dey ES, Buchweishaija J, Mkayula LL, Ye L. Isolation of anacardic acid from natural cashew nut shell liquid (CNSL) using supercritical carbon dioxide. J Agric Food Chem 2008;56:9350-4.

[8] Tyman JHP, Johnson RA, Muir M, Rokhgar R. The extraction of natural cashew nut-shell liquid from the cashew nut (Anacardium occidentole). J Am Oil Chem Soc 1989;66:553-7.

[9] Yuliana M, Tran-Thi NY, Ju YH. Effect of extraction methods on characteristic and composition of Indonesian cashew nut shell liquid. Ind Crop Prod 2012;35(1):230-6.

[10] Mriziq KS, Guiochon G. Column properties and flow profiles in over-pressured thin layer chromatography. J Chromatogr A 2008;1187:180-7.

[11] Majors RE. The cleaning and regeneration of HPLC reversed-phase HPLC columns. LGGC Eur Column Watch 2003;2-6.

[12] Liu HJ, Finch JW, Lavallee MJ, Collamati RA. Effects of column length, particle size, gradient length and flow rate on peak capacity of nano-scale liquid chromatography for peptide separations. J Chromatogr A 2007;1147:30-6.

[13] Snyder LR, Kirkland JJ. Introduction to modern liquid chromatography. New York, NY, U.S.A.: John Wiley and Sons Inc.; 1979

[14] Gunawan S, Ismadji S, Ju YH. Design and operation of a modified silica gel column chromatography. J Chin Inst Chem Eng 2008;39:625-33.

[15] Kim YN, Giraud DW, Driskell JA. Tocopherol and carotenoid contents of selected Korean fruits and vegetables. J Food Compos Anal 2007;20:458-65.

[16] Maia JGS, Andrade EHA, Zoghbi MGB. Volatile constituents of the leaves, fruits and flowers of cashew (Anacardium occidentale L.). J Food Compos Anal 2000;13:227-32. 